\title{
DIVERTÍCULO DE ZENKER
}

\section{ZENKER'S DIVERTICULUM}

\author{
Elmes Luis Andreis ${ }^{1}$ \\ Enilde Eloena Guerra, TCBC-RS ${ }^{2}$ \\ Rafael Rodrigues Lemos ${ }^{3}$
}

\section{INTRODUÇÃO}

O divertículo faringoesofágico é uma herniação da mucosa da parede posterior do hipofaringe e foi descrito inicialmente por Ludlow, há mais de 200 anos, e revisado pelo patologista alemão Zenker ${ }^{1}$. Desde então é chamado divertículo de Zenker (DZ).

Apresenta uma fisiopatologia não bem estabelecida, mas sugere-se que seja decorrente de altas pressões intraesofágicas sobre áreas frágeis da hipofaringe ${ }^{2}$. Os pacientes apresentam-se com quadro clínico característico e de fácil confirmação diagnóstica pela radiografia contrastada do esôfago-estômago-duodeno (REED) ${ }^{3}$. Embora haja relatos de tratamento endoscóspico dessa afecção com bons resultados, o tratamento cirúrgico continua sendo o de escolha na maioria dos serviços ${ }^{4,5}$.

\section{RELATO DOS CASOS}

No período de janeiro de 1994 a janeiro de 1997, seis pacientes com DZ foram diagnosticados e tratados no Hospital Nossa Senhora da Conceição. Os dados clínicos e terapêuticos dos pacientes foram revisados junto ao serviço de arquivo médico do Grupo Hospitalar Conceição de forma retrospectiva.

Dos seis pacientes, três eram do sexo masculino e três do sexo feminino. A média de idade foi de 70 anos; o tempo de evolução clínica até o momento do diagnóstico variou de seis meses a cinco anos (em dois casos o tempo de evolução não foi esclarecido). Todos os casos eram sintomáticos, sendo disfagia a principal queixa, seguida de regurgitação, halitose, emagrecimento, vômitos alimen- tares, disfonia, tumoração cervical redutível e tosse pósprandial. O diagnóstico definitivo foi feito através dos achados da REED em todos os casos e de endoscopia digestiva alta (EDA) complementar em dois casos (Figura 1). Não foi realizada manometria. Os divertículos mediam em média $4 \mathrm{~cm}$. Em todos os casos o tratamento foi cirúrgico e constou de miotomia ampla do músculo cricofaríngeo e diverticulectomia. O tempo médio da retirada da sonda nasogástrica foi de três dias, e a alimentação por via oral foi reiniciada em torno do quinto dia pós-operatório na maioria dos casos, com boa aceitação. Como complicações, dois pacientes evoluíram com infecção da ferida operatória, um deles cursando também com insuficiência respiratória. Ambos tiveram boa evolução. Não houve mortalidade operatória.

\section{DISCUSSÃo}

O divertículo de Zenker é o divertículo mais comum do esôfago (90\%); sua prevalência tem sido relatada como variando entre $0,01 \%$ e $0,11 \%$. Ocorre em maior número nos indivíduos com mais de 50 anos de idade, predominando em mulheres, segundo alguns estudos, e com maior frequiência em homens, de acordo com outros ${ }^{3}$.

O divertículo de Zenker, divertículo faringoesofágico ou hipofaríngeo, é um falso divertículo, visto que é composto somente de mucosa e de tecido areolar adjacente, herniando-se junto à parede posterior da hipofaringe. Há três sítios frágeis na parede muscular desse órgão: o triângulo de Killian (localizado entre o músculo constritor inferior do faringe e as fibras superiores do músculo cricofaríngeo), a área de Killian-Jamieson (entre fibras oblíquas e

1. Preceptor Chefe do Serviço de Cirurgia Geral do HNSC.

2. Preceptora do Serviço de Cirurgia Geral do HNSC. Mestre em Cirurgia pela UFRGS.

3. Residente de Cirurgia Geral do HNSC.

Recebido em 9/9/1997

Aceito para publicação em 18/1/2001

Trabalho realizado no Serviço de Cirurgia Geral do Hospital Nossa Senhora da Conceição - HNSC - Grupo Hospitalar Conceição - GHC - Porto Alegre-RS 


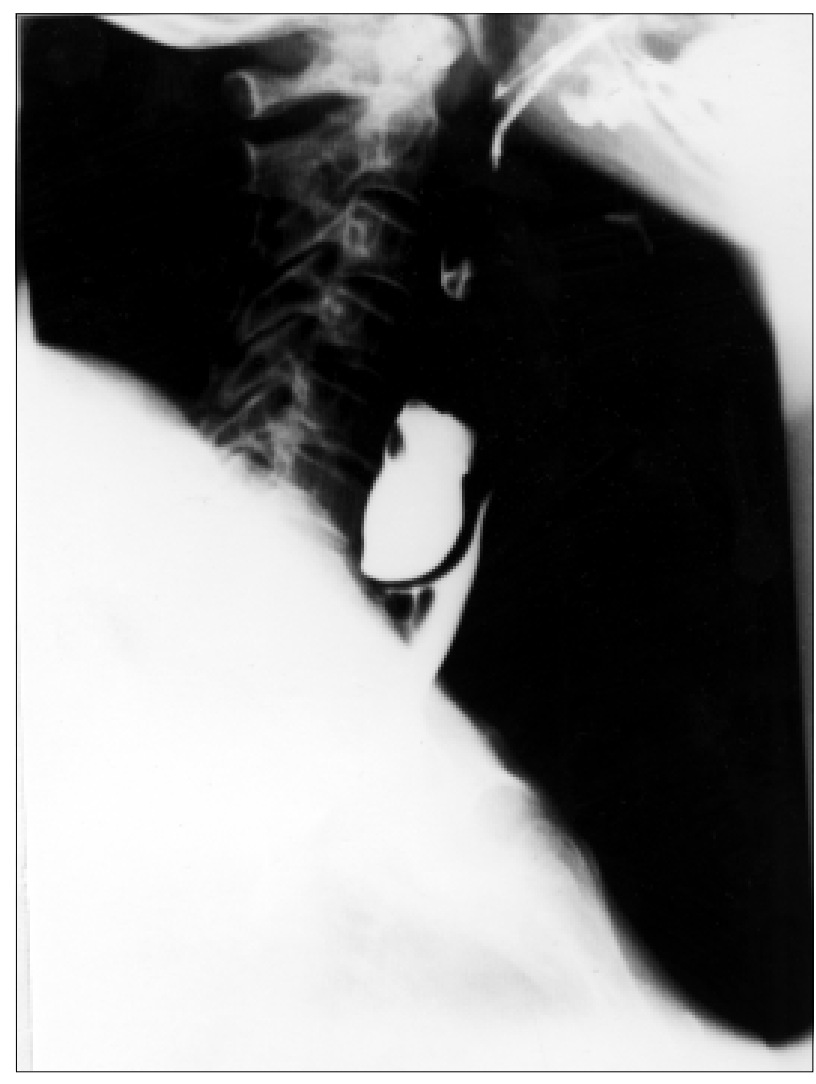

Figura 1 - REED de uma das pacientes relatada nesse estudo, mostrando a formação diverticular no nível cervical

as transversas do músculo cricofaríngeo) e o triângulo de Laimer (formado entre o músculo cricofaríngeo e as fibras circulares mais superiores da parede muscular esofagiana). O triângulo de Killian foi o ponto acometido em todos os casos e é o sítio de origem do DZ mais comum na maioria dos pacientes relatados na literatura.

A fisiopatologia da doença ainda não está bem estabelecida. Uma das teorias ressalta a presença, desde o nascimento, de um ponto muscular frágil em uma das localizações descritas, por onde, eventualmente, surge uma herniação. De acordo com a teoria da disfunção muscular, o DZ é um divertículo de pulsão, onde a herniação da mucosa é predisposta pela excessiva contração ou descoordenação dos músculos cricofaríngeos. Cook et al. ${ }^{2}$ mostram que a pressão hipofaríngea está aumentada durante o trânsito alimentar e suportam a hipótese original de Zenker, de que a bolsa é um divertículo de pulsão. Não concordam com a teoria da incoordenação muscular ou do chamado espasmo cricofaríngeo, mas ressaltam que a anormalidade primária nos pacientes com DZ é a abertura incompleta do esfíncter esofágico superior, mesmo com relaxamento completo do mesmo.

Os pacientes com DZ apresentam queixas comuns que incluem: disfagia, regurgitação, halitose, emagrecimento, vômitos alimentares, disfonia, tumoração cervical, tosse pós-prandial, odinofagia, sialorréia, pirose e dor cervical. Como complicações da doença, são relatadas: aspiração e pneumonia recurrentes, perfuração do divertículo, obstrução esofágica, degeneração neoplásica (incidência em torno de $0,25 \%-0,3 \%$ ), entre outras ${ }^{3}$. No presente estudo, apenas as cinco primeiras queixas citadas anteriormente foram relatadas, sendo a disfagia a mais freqüente e principal, e nenhuma das complicações foram observadas. $\mathrm{Na}$ maioria dos estudos já publicados até o momento, o diagnóstico do DZ por imagem foi realizado através da REED. Há autores que preconizam a realização de fluoroscopia e/ ou manometria para melhor avaliação da fisiopatologia da doença, cujo entendimento é essencial para a escolha da terapêutica cirúrgica a ser empregada. A EDA tem sido solicitada em casos especiais com outras queixas associadas $^{3}$. Dos casos relatados todos apresentaram confirmação diagnóstica através do REED e apenas dois realizaram EDA por apresentarem história e queixas concomitantes de úlcera péptica.

O tratamento do DZ é preferencialmente cirúrgico. Hoje, em contraste com condutas do passado, há consenso de que todo divertículo deva ser removido, dada a sua progressão certa em tamanho, sintomatologia e pontencialidade para complicações ${ }^{4}$. Ressaltam que os pacientes com divertículo de origem recente são usualmente assintomáticos e não requerem tratamento, e que a miotomia não é indicada a não ser que o DZ resulte em acalasia verdadeira do cricofaríngeo. Também inferem que esses devem ser encarados como achados incidentais em pacientes sem queixas esofágicas altas. Para Payne ${ }^{5}$, o tratamento cirúrgico está sempre indicado independente do tamanho ou da duração dos sintomas. Se o divertículo for pequeno, só deve ser realizada a miotomia; se for médio ou grande é feita diverticulectomia associada à miotomia cricofaríngea. Outros defendem a diverticulopexia, alegando que produz melhores resultados, com vantagens como alimentação oral e alta hospitalar precoces ${ }^{4,5}$.

Há mais de 30 anos a miotomia, com ou sem diverticulectomia, tem sido um procedimento padrão no manejo cirúrgico do DZ na maioria dos principais centros. A razão para maior uso da miotomia foram índices mais baixos de complicações e recidiva quando essa técnica era realizada. Todos os seis pacientes estudados foram submetidos à diverticulectomia e ampla miotomia, por apresentarem divertículos médios a grandes. A miotomia simples deve ser reservada apenas para aqueles assintomáticos e de pequeno tamanho $(<2 \mathrm{~cm})$.

\section{ABSTRACT \\ The authors show six cases os Zenker's diverticulum diagnosed and treated at Nossa Senhora da Conceição hospital from January 1994 to January 1997. All patients were syntomatics and underwent to myotomy of crico- pharyngeal upper muscle with diverticulectomy.}

Key Words: Zenker's diverticulum 


\section{REFERÊNCIAS}

1. Zenker FA, von Zeimnssen H. Krankheiten des Oesophagus. In: Zeimssen $\mathrm{H}$, ed Handbhch der speciellen payhologic und therapic, vol 7 (suppl). Leipzig:FC Vogel, 1877:187.

2. Cook IJ, Blumbergs P, Cash K, et al. Structural abnormalitics of the cricopharyngeous muscle in patients with pharyngeal (Zenker's) diverticulum. J Gastrenterol Hepatol, 1992; 7: 556-562.

3. Laccourreye O, Ménard M, Caucjois R, et al. Esophageal diverticulum: diverticulopexy versus diverticulectomy. Laryngoscope, 1994; 104: 889-892.

4. Watemberg S, Landau O, Avrahami R. Zenker's Diverticulum: Reappraisal. Am J Gastr, 1996; 91: 1494 - 1498.
5. Payne WS, Clagett OT. Pharyngeal and esophageal diverticula. Curr Probl Surg, 1965; 1: 1-31.

Endereço para correspondência:

Dra. Enilde Eloena Guerra

Rua Adão Baino, 225/210 - Bairro Cristo Redentor

91350-240 — Porto Alegre-RS 